\title{
Factors associated with a SARS-CoV-2 recurrence after hospital discharge among patients with COVID-19: systematic review and meta-analysis ${ }^{* \#}$
}

\author{
Meng-qi YAO ${ }^{\S 1}$, Qiu-xian ZHENG ${ }^{\S 2}$, Jia XU², Jing-wen $\mathrm{DENG}^{2}$, Tian-tian $\mathrm{GE}^{2}$, Hai-bo ZHOU², \\ Feng-tian $\mathrm{WU}^{2}$, Xin-yu GU ${ }^{2}$, Qin $\mathrm{YANG}^{2}$, Yan-li REN ${ }^{2}$, Gang WANG ${ }^{2}$, Zhi CHEN ${ }^{\dagger ‡ 2}$ \\ ${ }^{1}$ Zhejiang University School of Public Health, Hangzhou 310058, China \\ ${ }^{2}$ State Key Laboratory for Diagnosis and Treatment of Infectious Diseases, National Clinical Research Center for Infectious Diseases, \\ Collaborative Innovation Center for Diagnosis and Treatment of Infectious Diseases, the First Affiliated Hospital, School of Medicine, \\ Zhejiang University, Hangzhou 310003, China \\ ${ }^{\dagger}$ E-mail: chenzhi@zju.edu.cn
}

Received June 7, 2020; Revision accepted July 26, 2020; Crosschecked Nov. 16, 2020

\begin{abstract}
Background: The proportion of recurrences after discharge among patients with coronavirus disease 2019 (COVID-19) was reported to be between $9.1 \%$ and $31.0 \%$. Little is known about this issue, however, so we performed a meta-analysis to summarize the demographical, clinical, and laboratorial characteristics of non-recurrence and recurrence groups. Methods: Comprehensive searches were conducted using eight electronic databases. Data regarding the demographic, clinical, and laboratorial characteristics of both recurrence and non-recurrence groups were extracted, and quantitative and qualitative analyses were conducted. Results: Ten studies involving 2071 COVID-19 cases were included in this analysis. The proportion of recurrence cases involving patients with COVID-19 was $17.65 \%$ (between $12.38 \%$ and $25.16 \%$ ) while older patients were more likely to experience recurrence (weighted mean difference $(\mathrm{WMD})=1.67$, range between 0.08 and 3.26). The time from discharge to recurrence was $13.38 \mathrm{~d}$ (between 12.08 and $14.69 \mathrm{~d}$ ). Patients were categorized as having moderate severity (odds ratio $(\mathrm{OR})=2.69$, range between 1.30 and 5.58), while those with clinical symptoms including cough $(\mathrm{OR}=5.52$, range between 3.18 and 9.60$)$, sputum production $(\mathrm{OR}=5.10$, range between 2.60 and 9.97 ), headache ( $\mathrm{OR}=3.57$, range between 1.36 and 9.35), and dizziness $(\mathrm{OR}=3.17$, range between 1.12 and 8.96$)$ were more likely to be associated with recurrence. Patients presenting with bilateral pulmonary infiltration and decreased leucocyte, platelet, and $\mathrm{CD} 4^{+} \mathrm{T}$ counts were at risk of COVID-19 recurrence $(O R=1.71$, range between 1.07 and $2.75 ; W M D=-1.06$, range between -1.55 and -0.57 , $W M D=-40.39$, range between -80.20 and -0.48 , and $W M D=-55.26$, range between -105.92 and -4.60 , respectively). Conclusions: The main factors associated with the recurrence of severe acute respiratory syndrome coronavirus 2 (SARS-CoV-2) after hospital discharge were older age, moderate severity, bilateral pulmonary infiltration, laboratory findings including decreased leucocytes, platelets, and $\mathrm{CD}^{+} \mathrm{T}$ counts, and clinical symptoms including cough, sputum production, headache, and dizziness. These factors can be considered warning indicators for the recurrence of SARS-CoV-2 and might help the development of specific management strategies.
\end{abstract}

Key words: Recurrence case; Severe acute respiratory syndrome coronavirus 2 (SARS-CoV-2); Risk factor; Meta-analysis https://doi.org/10.1631/jzus.B2000304

CLC number: R512.99

\footnotetext{
¿ Corresponding author

$\S$ The two authors contributed equally to this work

* Project supported by the National Science and Technology Major Project of China (Nos. 2018ZX10302206 and 2017ZX10202203) and the Zhejiang University Academic Award for Outstanding Doctoral Candidates (No. 2020052), China

\# Electronic supplementary materials: The online version of this article (https://doi.org/10.1631/jzus.B2000304) contains supplementary materials, which are available to authorized users

(6) ORCID: Zhi CHEN, https://orcid.org/0000-0002-0848-1502

(c) Zhejiang University and Springer-Verlag GmbH Germany, part of Springer Nature 2020
} 


\section{Introduction}

Subsequent to the first report of coronavirus disease 2019 (COVID-19) in December 2019, this disease has spread rapidly worldwide (Chen NS et al., 2020). We know that the clinical spectrum of COVID19 ranges widely from asymptomatic infections to death (Zhang et al., 2020). As we have developed a deeper understanding of COVID-19, progress has been made in treatment. In China, 83022 cases were reported as of June 4, 2020, and 78319 of these were cured and patients were discharged (National Health Commission of the People's Republic of China, 2020) According to the World Health Organization's guidelines and scheme of diagnosis and treatment of COVID-19 (Trial 7th Edition), patients who meet discharge criteria should have at least two consecutive negative nucleic acid test results conducted over an interval of at least $24 \mathrm{~h}$ (Medical Administration and Hospital Authority, 2020; Rothan and Byrareddy, 2020). The recurrence of a positive severe acute respiratory syndrome coronavirus 2 (SARS-CoV-2) RNA test result was found in some discharged patients (Chen DB et al., 2020; Hoang et al., 2020). This phenomenon raises the concern that discharged patients may be at risk of viral reactivation and should be considered potential sources of SARS-CoV-2 infection.

The proportion of recurrence cases after discharge among patients with COVID-19 is between 9.09\% and $30.77 \%$ (Li YJ et al., 2020; Xiao et al., 2020; Ye et al., 2020). The short inter-episode period from discharge to first recurrence was $5 \mathrm{~d}$ in these cases (Yuan et al., 2020). The reasons why SARSCoV-2 RNA has been re-detected in some discharged patients remain unclear. A number of studies have explored the factors involved in this phenomenon. Zhuo et al. (2020) reported that fever on admission is as an independent risk factor that can be used to predict recurrence outcome. A number of demographical and clinical factors including age, body mass index (BMI), and low levels of some blood parameters have been found to be driving forces in a recurrence prediction model (Huang et al., 2020). Data show that specific characteristics exhibit substantial differences between non-recurrence and recurrence groups (Jiang et al., 2020). We therefore performed a systematic review and meta-analysis to summarize data on de- mographic characteristics, clinical features, and laboratory findings in non-recurrence and recurrence groups as well as to explore critical factors associated with COVID-19 recurrence. These might provide more evidence for implementing preventive and controllable strategies for recurrence cases.

\section{Methods}

\subsection{Search strategy and selection criteria}

Studies published between May 1st, 2020 and May 29th, 2020 were comprehensively interrogated via the Web of Science, PubMed, medRxiv, bioRxiv, China National Knowledge Infrastructure (CNKI), SinoMed, VIP, and Wangfang databases. Search terms were "COVID-19," "2019-nCoV," "SARS-CoV-2," "severe acute respiratory syndrome coronavirus 2," "recurrence," "reinfection," "reactivation," "re-positive," and related terms. Details are presented in Table S1.

\subsection{Inclusion and exclusion criteria}

The inclusion criteria used in this analysis were: (1) negative on two consecutive reverse transcriptasepolymerase chain reaction (RT-PCR) tests at least $24 \mathrm{~h}$ apart before being discharged and later presented with recurrence of SARS-CoV-2; (2) recurrence of SARS-CoV-2 among patients with COVID-19 as confirmed using RT-PCR; (3) studies with sufficient data to describe epidemiological and clinical characteristics of both recurrence and non-recurrence cases.

The exclusion criteria used in this analysis were: (1) studies with recurrence cases only; (2) duplicated publication data; (3) studies missing key data; (4) case reports, reviews, and studies lacking original data.

\subsection{Data extraction and quality assessment}

The following information was extracted from each study: first author, title, journal name, publication date, study periods, regions, sample size, demographic data (e.g., gender, age), chronic medical conditions (e.g., comorbidities, smoking history), clinical features (e.g., fever, headache), laboratory results (e.g., leukocytes, neutrophils), and radiographical features (e.g., ground-glass opacity, bilateral pulmonary infiltration). Three components, including selection, comparability, and exposure or outcome, were assessed for each study using the Newcastle-Ottawa 
Scale (Jaiswal et al., 2018; Xu and Lu, 2019). This consisted of eight items with a full score of nine stars (Stang, 2010). EndNote (Version X9) was used to manage the articles and citations.

\subsection{Statistical analysis}

The online tool developed by Luo et al. (2018) was used to convert median and interquartile range $(\mathrm{IQR}) /$ range to mean and standard deviation for continuous variables. Statistical differences between continuous variables were then evaluated using the weighted mean difference (WMD) and a $95 \%$ confidence interval $(95 \% \mathrm{CI})$, while the odds ratio (OR) and its $95 \% \mathrm{CI}$ were calculated to estimate whether, or not, categorical variables increased the risk of SARS-CoV-2 recurrence. Heterogeneity amongst each study was then assessed using $I^{2}$; thus, when $I^{2}>50 \%$, a random-effect model was chosen, otherwise a fixed effect model was used (Ades et al., 2005). Potential publication bias was appraised using a funnel plot and Egger weighted regression (Peters et al., 2006). The software R (Version 3.2.3) was used for data clearing and analyses.

\section{Results}

\subsection{Search results}

A total of 999 records were identified via a database search. Titles and abstracts of 481 published studies were then screened after discarding duplicates and 56 articles were selected for detailed assessment. Subsequent to applying exclusion criteria, 10 studies consisting of 1803 non-recurrence and 268 recurrence cases were included in a meta-analysis (Fig. 1). Details are presented in Table 1.

\subsection{Demographical and time interval features of recurrence cases}

The overall proportion of recurrence cases of SARS-CoV-2 among the patients with COVID-19 was $17.65 \%$ (95\% CI: range between $12.38 \%$ and $25.16 \%$; Figs. S1 and 2). Patients in recurrence cases were found to be older than those in non-recurrence cases (WMD $=1.67,95 \% \mathrm{CI}$ : range between 0.08 and 3.26), Data show that BMI was lower in recurrence than in non-recurrence cases (WMD $=-1.20,95 \% \mathrm{CI}$ : range between -2.05 and -0.35 ). No statistical dif- ferences were seen in the time from onset to negative SARS-CoV-2 RNA test results between recurrence and non-recurrence groups. The time from discharge to recurrence of SARS-CoV-2 was $13.38 \mathrm{~d}$ (95\% CI: range between 12.08 and $14.69 \mathrm{~d}$; Table 2).

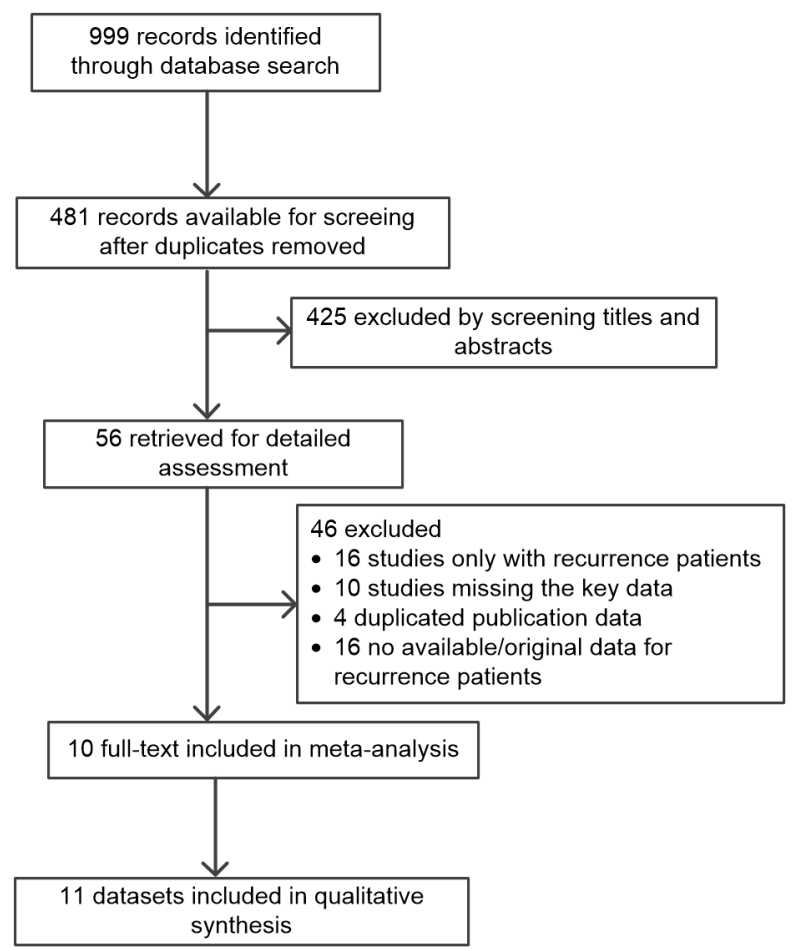

Fig. 1 Flow diagram of the study selection process for meta-analysis

\subsection{Clinical data on recurrence cases}

Patients were categorized as having moderate severity conditions $(\mathrm{OR}=2.69,95 \% \mathrm{CI}$ : range between 1.30 and 5.58) while those with clinical symptoms including cough $(\mathrm{OR}=5.52,95 \% \mathrm{CI}$ : range between 3.18 and 9.60$)$, sputum production $(\mathrm{OR}=5.10,95 \% \mathrm{CI}$ : range between 2.61 and 9.97), headache $(\mathrm{OR}=3.57$, 95\% CI: range between 1.36 and 9.35), and dizziness $(\mathrm{OR}=3.17,95 \% \mathrm{CI}$ : range between 1.12 and 8.96$)$ were more likely to experience recurrence. Patients who presented with bilateral pulmonary infiltration were also at risk of recurrence $(\mathrm{OR}=1.71,95 \% \mathrm{CI}$ : range between 1.07 and 2.75; Figs. S2a and 3a). Laboratory findings show that leucocytes (WMD $=-1.06$, 95\% CI: range between -1.55 and -0.57 ), platelets $(\mathrm{WMD}=-40.39,95 \% \mathrm{CI}$ : range between -80.20 and -0.48 ), and $\mathrm{CD}^{+} \mathrm{T}$ (WMD $=-55.26,95 \% \mathrm{CI}$ : range 
Table 1 Studies and characteristics of COVID-19 patients included in this meta-analysis

\begin{tabular}{|c|c|c|c|c|c|}
\hline Study & Journal name & Study period (year-month-day) & Region & Sample size & Quality \\
\hline Chen J et al., 2020 & Aging & $2020 / 02 / 24-2020 / 04 / 15$ & Wuhan, China & 1067 & 6 \\
\hline Jiang et al., 2020 & Journal of Infection & $2020 / 01 / 28-2020 / 03 / 13$ & Henan, China & 35 & 4 \\
\hline An et al., 2020 & $\begin{array}{l}\text { Annals of Translational } \\
\text { Medicine }\end{array}$ & $2020 / 01 / 23-2020 / 02 / 25$ & Guangdong, China & 242 & 6 \\
\hline Zhuo et al., 2020 & $\begin{array}{l}\text { The Journal of Practical } \\
\text { Medicine }\end{array}$ & $2020 / 01 / 23-2020 / 03 / 03$ & Guangdong, China & 34 & 5 \\
\hline Li Q et al., 2020 & Chongqing Medicine & $2020 / 01 / 18-2020 / 03 / 15$ & Chongqing, China & 20 & 6 \\
\hline Wong et al., 2020 & Journal of Medical Virology & $2020 / 01 / 01-2020 / 04 / 12$ & Darussalam, Brunei & 106 & 6 \\
\hline Huang et al., 2020 & medRxiv & $2020 / 01 / 11-2020 / 04 / 23$ & Shenzhen, China & 414 & 6 \\
\hline Hu et al., 2020 & JAMA Network Open & $2020 / 01 / 25-2020 / 02 / 26$ & Guizhou, China & 69 & 6 \\
\hline Zhao et al., 2020 & Clinical Pediatrics & $2020 / 01 / 21-2020 / 04 / 18$ & Beijing, China & 14 & 5 \\
\hline Xiao et al., 2020 & Journal of Medical Virology & $2020 / 01 / 21-2020 / 02 / 12$ & Wuhan, China & 70 & 6 \\
\hline
\end{tabular}

Table 2 WMD and 95\% CI of demographical and time interval between recurrence and non-recurrence of COVID-19 patients

\begin{tabular}{lccr}
\hline \multicolumn{1}{c}{ Demographical and time interval } & Number of studies & WMD/OR $(95 \% \mathrm{CI})$ & Heterogeneity, $I^{2}(\%)$ \\
\hline Age $($ year) & 8 & $1.67(0.08,3.26)$ & 0 \\
BMI $\left(\mathrm{kg} / \mathrm{m}^{2}\right)$ & 2 & $-1.20(-2.05,-0.35)$ & 0 \\
Time from onset to RNA negative (d) & 4 & $2.32(-3.61,8.25)$ & 92.10 \\
Time from discharge to recurrence (d) & 2 & $13.38(12.08,14.69)$ & 0 \\
\hline
\end{tabular}

WMD, weighted mean difference; CI, confidence interval; OR, odds ratio; BMI, body mass index

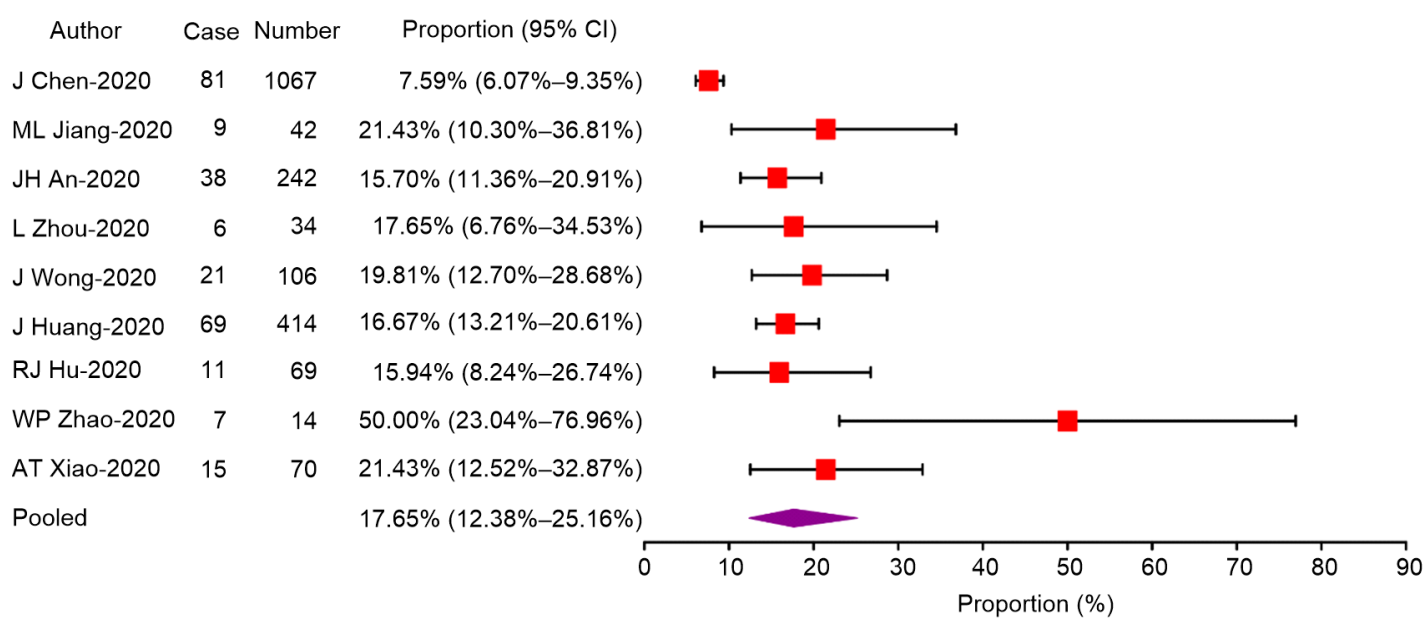

Fig. 2 Overall proportion of recurrence cases among the COVID-19 patients

between -105.92 and -4.60$)$ all decreased in recurrence cases (Figs. S2b and 3b). The publication bias of the recurrence case proportion among the COVID19 patients was illustrated in Fig. S3.

\section{Discussion}

Subsequent to the outbreak of SARS in 2002 and Middle East respiratory syndrome (MERS) in 2012, coronavirus $(\mathrm{CoV})$ transmission between animals and humans has been confirmed (Cauchemez et al., 2013; Cui et al., 2019). This is important because as CoVs are an emerging infectious agent, a number of notable studies have been conducted to explore the biological, epidemiological, and clinical characteristics of the new CoV (Khose et al., 2020; Li TS et al., 2020; Radzikowska et al., 2020). Throughout the early COVID-19 epidemic, the recurrence of positive SARSCoV-2 RNA test results after hospital discharge 
(a)

Moderate
Headache
Cough
Sputum production
Dizziness
Bilateral pulmonary infiltration

OR $(95 \%$ Cl)

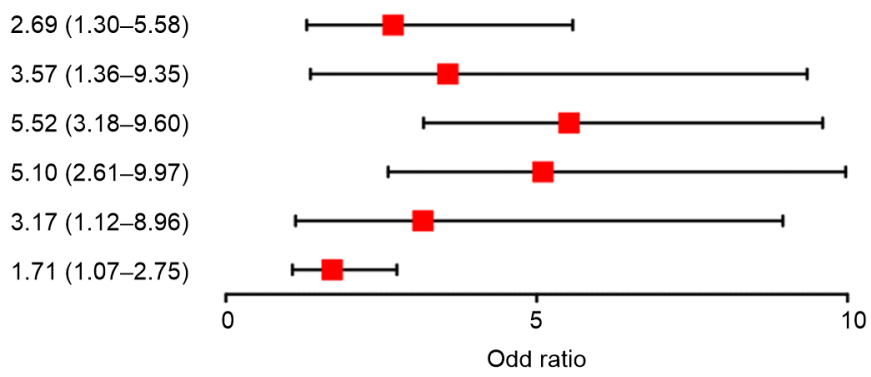

(b) Characteristics $\operatorname{WMD}(95 \% \mathrm{Cl})$

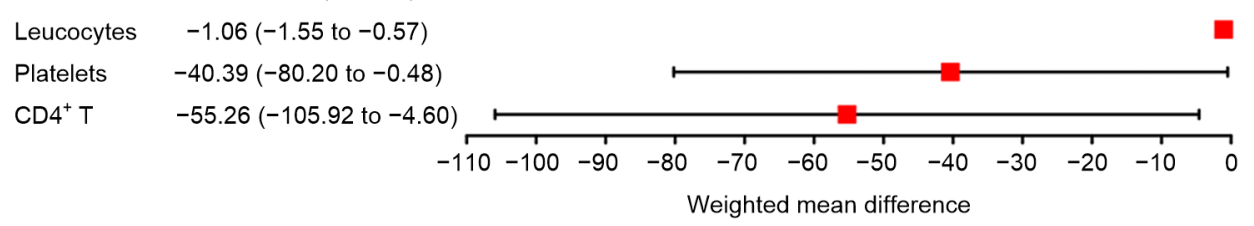

Fig. 3 Clinical characteristic and laboratory findings associated with recurrence cases OR, odds ratio; CI, confidence interval; WMD, weighted mean difference

appeared in at least seven provinces in China while approximately $14 \%$ of discharged patients in Guangdong Province experienced recurrences ( $\mathrm{Li}$ and Huang, 2020). A comprehensive understanding of this phenomenon is lacking, however.

Patient outcomes are often influenced by numerous factors. The proportion of recurrence cases among patients with COVID-19 was $17.65 \%$ while the median time between discharge and the recurrence of a positive SARS-CoV-2 RNA test result was $13.38 \mathrm{~d}$. In order to detect recurrence cases early, the diagnosis and treatment of COVID-19 (Trial 7th Edition) should follow a revised management strategy of the discharged patient from "should continue $14 \mathrm{~d}$ self-health condition monitoring" to "continue $14 \mathrm{~d}$ isolation management and health condition monitoring" ( $\mathrm{Li}$ and Huang, 2020). Results show that older aged people are at higher risk of positive SARSCoV-2 RNA recurrence. Previous research has shown that older people are more likely to develop severe COVID-19 and even die (Wu and McGoogan, 2020). Thus, due to poor self-health status, lower immunity, and chronic medical conditions, older patients have relatively weak virus clearance rates and tolerance, and may lead to recurrence. Moderate severity cases easily developed into recurrence cases, a conclusion supported by previous work (Xiao et al., 2020). Data show statistical differences between cough and sputum production both recurred and did not in the study of Huang et al. (2020). These cases are associated with a higher risk of recurrence. Headaches and dizziness are the most common neurological manifestations associated with COVID-19; however, detailed mechanisms have yet not to be reported and so further research is needed (Ahmad and Rathore, 2020). Integrated into larger-scale sample sizes from each research, headaches and dizziness were also associated with recurrence. Thus, in the study of Chen J et al. (2020), elevated interleukin-6 (IL-6) levels and increased lymphocytes were also shown to be risk factors associated with recurrence. In our study, patients with bilateral pulmonary infiltration and decreased leucocyte, platelet, and $\mathrm{CD}^{+} \mathrm{T}$ counts were more likely to experience recurrence. Indeed, in multivariate regression analysis, patients who presented with bilateral pulmonary infiltration turned out to be at serve recurrence risk for positive SARS-CoV-2 RNA. Chen $\mathrm{J}$ et al. (2020) assumed that these results may be attributed to potentially undetectable amount of SARS$\mathrm{CoV}-2$ which persists in respiratory epithelia during patient recovery. SARS-CoV-2 infection can also lead to a severe dysfunctional immune response (Hui et al., 2020). Studies have also shown that patients with abnormal, over-activated immunity and "cytokine storms," characterized as immune cell infiltration and elevated pro-inflammatory cytokine release, are also at high risk (Liu S et al., 2020; Song et al., 2020). Immune cells such as white blood cells enable the body to defend itself against external infections and play an important role in response to viruses (Liu W 
et al., 2020). Guo et al. (2019) previously reported that $\mathrm{CD}^{+}{ }^{+} \mathrm{T}, \mathrm{CD}^{+} \mathrm{CD}^{+} \mathrm{T}$, and $\mathrm{CD} 3^{+} \mathrm{CD}^{+}{ }^{+} \mathrm{T}$ cells significantly decreased in fatal COVID-19 cases (Guo et al., 2019; Zhou et al., 2020). Over-activated T and $\mathrm{T}$-cell inhibitory factor expression may also lead to decreased $\mathrm{T}$ cell exhaustion (Altmann and Boyton, 2020; Bellesi et al., 2020; Remy et al., 2020). Decreased cellular immune function might also lead to incomplete virus clearance and recurrences. Indeed, in study of Lippi et al. (2020), a lower platelet count was significantly correlated with severe COVID-19 and death cases while thrombocytopenia in COVID-19 implies serious organ malfunction or physiologic decompensation. The progression of COVID-19 promotes the activation of platelets and alters their function, which means that SARS-CoV-2 interacts with platelets during the infection process (Hottz et al., 2020). These results may explain the lower platelet count, also found in recurrence cases.

Several other possible factors could also induce a SARS-CoV-2 recurrence. Firstly, false-negative RT-PCR results are due to sample sources, sampling procedures, and sensitivity/specificity of a test kit (Yang et al., 2020). Secondly, SARS-CoV-2 RNA shed in feces from at least two weeks to more than one month, and up to a maximum of $83 \mathrm{~d}$ has also been reported (Cai et al., 2020; Li N et al., 2020). Thirdly, when the body is infected with a virus, a specific antibody is produced and therefore a body will have a certain period of protection against secondary infections. It remains unknown whether, or not, recovered patients will be immune when exposed again to the virus.

\section{Conclusions}

A total of 1803 cases of non-recurrence as well as 268 recurrences were included in this study to analyze the factors contributing to SARS-CoV-2 reappearances. Older age, moderately severe cases, and clinical manifestations including cough, sputum production, headache, and dizziness are all recurrence risk factors. Radiographic signs and laboratory findings including bilateral pulmonary infiltration as well as decreased numbers of leucocytes, platelets, and $\mathrm{CD}^{+} \mathrm{T}$ cells are more likely associated with SARSCoV-2 recurrences. These factors should be consid- ered as early warning signs for recurrence. It is therefore necessary to self-quarantine for $14 \mathrm{~d}$ after discharge, while process management from diagnosis, isolation, and treatment to discharge requires strict control.

\section{Contributors}

Zhi CHEN, Meng-qi YAO, and Qiu-xian ZHENG designed the analysis. Meng-qi YAO, Qiu-xian ZHENG, and Jia XU finished the analysis and prepared the manuscript. Jing-wen DENG, Tian-tian GE, Hai-bo ZHOU, and Feng-tian WU prepared the figures and tables. Xin-yu GU, Qin YANG, Yan-li REN, and Gang WANG prepared the tables and edited this manuscript. Zhi CHEN supervised the study. All authors reviewed and approved the final version of the manuscript.

\section{Compliance with ethics guidelines}

Meng-qi YAO, Qiu-xian ZHENG, Jia XU, Jing-wen DENG, Tian-tian GE, Hai-bo ZHOU, Feng-tian WU, Xin-yu GU, Qin YANG, Yan-li REN, Gang WANG, and Zhi CHEN declare that they have no conflict of interest.

This article does not contain any studies with human or animal subjects performed by any of the authors.

\section{References}

Ades AE, Lu G, Higgins JPT, 2005. The interpretation of random-effects meta-analysis in decision models. Med Decis Making, 25(6):646-654. https://doi.org/10.1177/0272989x05282643

Ahmad I, Rathore F, 2020. Neurological manifestations and complications of COVID-19: a literature review. J Clin Neurosci, 77:8-12. https://doi.org/10.1016/j.jocn.2020.05.017

Altmann DM, Boyton RJ, 2020. SARS-CoV-2 T cell immunity: specificity, function, durability, and role in protection. Sci Immunol, 5(49):eabd6160. https://doi.org/10.1126/sciimmunol.abd6160

An JH, Liao XJ, Xiao TY, et al., 2020. Clinical characteristics of the recovered COVID-19 patients with re-detectable positive RNA test. Ann Transl Med, 8(17):1-12. https://doi.org/10.21037/atm-20-5602

Bellesi S, Metafuni E, Hohaus S, et al., 2020. Increased CD95 (Fas) and PD-1 expression in peripheral blood T lymphocytes in COVID-19 patients. Br J Haematol, 191(2): 207-211. https://doi.org/10.1111/bjh.17034

Cai JH, Xu J, Lin DJ, et al., 2020. A case series of children with 2019 novel coronavirus infection: clinical and epidemiological features. Clin Infect Dis, 71(6):1547-1551. https://doi.org/10.1093/cid/ciaa198

Cauchemez S, van Kerkhove MD, Riley S, et al., 2013. Transmission scenarios for Middle East respiratory syndrome coronavirus (MERS-CoV) and how to tell them apart. Euro Surveill, 18(24):20503. 
Chen DB, Xu WX, Lei ZY, et al., 2020. Recurrence of positive SARS-CoV-2 RNA in COVID-19: a case report. Int $J$ Infect Dis, 93:297-299. https://doi.org/10.1016/j.ijid.2020.03.003

Chen J, Xu XP, Hu J, et al., 2020. Clinical course and risk factors for recurrence of positive SARS-CoV-2 RNA: a retrospective cohort study from Wuhan, China. Aging, 12(17):16675-16689. https://doi.org/10.18632/aging.103795

Chen NS, Zhou M, Dong X, et al., 2020. Epidemiological and clinical characteristics of 99 cases of 2019 novel coronavirus pneumonia in Wuhan, China: a descriptive study. Lancet, 395(10223):507-513. https://doi.org/10.1016/s0140-6736(20)30211-7

Cui J, Li F, Shi ZL, 2019. Origin and evolution of pathogenic coronaviruses. Nat Rev Microbiol, 17(3):181-192. https://doi.org/10.1038/s41579-018-0118-9

Guo LX, Wei D, Zhang XX, et al., 2019. Clinical features predicting mortality risk in patients with viral pneumonia: the MuLBSTA score. Front Microbiol, 10:2752. https://doi.org/10.3389/fmicb.2019.02752

Hoang VT, Dao TL, Gautret P, 2020. Recurrence of positive SARS-CoV-2 in patients recovered from COVID-19. $J$ Med Virol, 92(11):2366-2367. https://doi.org/10.1002/jmv.26056

Hottz ED, Azevedo-Quintanilha IG, Palhinha L, et al., 2020. Platelet activation and platelet-monocyte aggregate formation trigger tissue factor expression in patients with severe COVID-19. Blood, 136(11):1330-1341. https://doi.org/10.1182/blood.2020007252

Hu RJ, Jiang ZX, Gao HM, et al., 2020. Recurrent positive reverse transcriptase-polymerase chain reaction results for coronavirus disease 2019 in patients discharged from a hospital in China. JAMA Netw Open, 3(5):e2010475. https://doi.org/10.1001/jamanetworkopen.2020.10475

Huang J, Zheng L, Li Z, et al., 2020. Recurrence of SARSCoV-2 PCR positivity in COVID-19 patients: a single center experience and potential implications. medRxiv, preprint. https://doi.org/10.1101/2020.05.06.20089573

Hui KPY, Cheung MC, Perera RAMP, et al., 2020. Tropism, replication competence, and innate immune responses of the coronavirus SARS-CoV-2 in human respiratory tract and conjunctiva: an analysis in ex-vivo and in-vitro cultures. Lancet Respir Med, 8(7):687-695. https://doi.org/10.1016/s2213-2600(20)30193-4

Jaiswal S, Liu XB, Wei QC, et al., 2018. Effect of corticosteroids on atrial fibrillation after catheter ablation: a meta-analysis. J Zhejiang Univ-Sci B (Biomed \& Biotechnol), 19(1):57-64. https://doi.org/10.1631/jzus.B1600529

Jiang ML, Li Y, Han ML, et al., 2020. Recurrent PCR positivity after hospital discharge of people with coronavirus disease 2019 (COVID-19). J Infect, 81(1):147-178. https://doi.org/10.1016/j.jinf.2020.03.024

Khose S, Moore JX, Wang HE, 2020. Epidemiology of the 2020 pandemic of COVID-19 in the state of Texas: the first month of community spread. J Community Health, 45(4):696-701.

https://doi.org/10.1007/s10900-020-00854-4

Li LQ, Huang SL, 2020. Whether the repositive rate of $14 \%$ of discharged patients in guangdong is infectious is not clear. Caixin (in Chinese). http://china.caixin.com/2020-02-25/ 101520334.html

Li N, Wang X, Lv TF, 2020. Prolonged SARS-CoV-2 RNA shedding: not a rare phenomenon. J Med Virol, 92(11): 2286-2287. https://doi.org/10.1002/jmv.25952

Li Q, Zhang H, Deng SY, et al., 2020. Expression and morphological analysis of peripheral blood lymphocytes subsets in patients with 2019 noval coronavirus. Chongqing $\mathrm{Med}$, online (in Chinese).

Li TS, Lu HZ, Zhang WH, 2020. Clinical observation and management of COVID-19 patients. Emerg Microbes Infect, 9(1):687-690.

https://doi.org/10.1080/22221751.2020.1741327

Li YJ, Hu YY, Yu YY, et al., 2020. Positive result of SarsCov-2 in faeces and sputum from discharged patient with COVID-19 in Yiwu, China. J Med Virol, 92(10):19381947.

https://doi.org/10.1002/jmv.25905

Lippi G, Plebani M, Henry BM, 2020. Thrombocytopenia is associated with severe coronavirus disease 2019 (COVID19) infections: a meta-analysis. Clin Chim Acta, 506:145148. https://doi.org/10.1016/j.cca.2020.03.022

Liu S, Zhi YX, Ying S, 2020. COVID-19 and asthma: reflection during the pandemic. Clin Rev Allergy Immunol, 59(1):78-88. https://doi.org/10.1007/s12016-020-08797-3

Liu W, Tao ZW, Wang L, et al., 2020. Analysis of factors associated with disease outcomes in hospitalized patients with 2019 novel coronavirus disease. Chin Med J, 133(9): 1032-1038. https://doi.org/10.1097/cm9.0000000000000775

Luo DH, Wan X, Liu JM, et al., 2018. Optimally estimating the sample mean from the sample size, median, mid-range, and/or mid-quartile range. Stat Methods in Med Res, 27(6): 1785-1805. https://doi.org/10.1177/0962280216669183

Medical Administration and Hospital Authority, 2020. National Health Commission's COVID-19 Diagnosis and Treatment Protocol (Trial Version 7) (in Chinese). http://www.nhc. gov.cn/yzygj/s7652m/202003/a31191442e29474b98bfed 5579d5af95.shtml

National Health Commission of the People's Republic of China, 2020. Update on COVID-19 as of 24:00, March 17 (in Chinese). http://www.nhc.gov.cn/xcs/yqtb/202003/97 b96f03fa3c4e8d8d0bf536271a10c0.shtml

Peters JL, Sutton AJ, Jones DR, et al., 2006. Comparison of two methods to detect publication bias in meta-analysis. JAMA, 295(6):676-680. https://doi.org/10.1001/jama.295.6.676 
Radzikowska U, Ding M, Tan G, et al., 2020. Distribution of ACE2, CD147, CD26, and other SARS-CoV-2 associated molecules in tissues and immune cells in health and in asthma, COPD, obesity, hypertension, and COVID-19 risk factors. Allergy, 75(11):2829-2845. https://doi.org/10.1111/all.14429

Remy KE, Mazer M, Striker DA, et al., 2020. Severe immunosuppression and not a cytokine storm characterizes COVID-19 infections. JCI Insight, 5(17):e140329. https://doi.org/10.1172/jci.insight.140329

Rothan HA, Byrareddy SN, 2020. The epidemiology and pathogenesis of coronavirus disease (COVID-19) outbreak. J Autoimmun, 109:102433. https://doi.org/10.1016/j.jaut.2020.102433

Song JW, Zhang C, Fan X, et al., 2020. Immunological and inflammatory profiles in mild and severe cases of COVID-19. Nat Commun, 11(1):3410. https://doi.org/10.1038/s41467-020-17240-2

Stang A, 2010. Critical evaluation of the Newcastle-Ottawa scale for the assessment of the quality of nonrandomized studies in meta-analyses. Eur J Epidemiol, 25(9):603605. https://doi.org/10.1007/s10654-010-9491-z

Wong J, Koh WC, Momin RN, et al., 2020. Probable causes and risk factors for positive SARS-CoV-2 test in recovered patients: evidence from Brunei Darussalam. J Med Virol, 92(11):2847-2851.

https://doi.org/10.1002/jmv.26199

Wu ZY, McGoogan JM, 2020. Characteristics of and important lessons from the coronavirus disease 2019 (COVID-19) outbreak in China: summary of a report of 72314 cases from the Chinese Center for Disease Control and Prevention. JAMA, 323(13):1239-1342. https://doi.org/10.1001/jama.2020.2648

Xiao AT, Tong YX, Zhang S, 2020. False negative of RT-PCR and prolonged nucleic acid conversion in COVID-19: rather than recurrence. J Med Virol, 92(10):1755-1756. https://doi.org/10.1002/jmv. 25855

Xu YG, Lu YQ, 2019. Systematic review and meta-analysis of the efficacy and safety of immunosuppressive pulse therapy in the treatment of paraquat poisoning. $J$ Zhejiang Univ-Sci B (Biomed \& Biotechnol), 20(7):588-597. https://doi.org/10.1631/jzus.B1800640

Yang Y, Yang MH, Shen CG, et al., 2020. Laboratory diagnosis and monitoring the viral shedding of SARSCoV-2 infections. Innovation, 1(3):100061. https://doi.org/j.xinn.2020.100061

Ye GM, Pan ZY, Pan YB, et al., 2020. Clinical characteristics of severe acute respiratory syndrome coronavirus 2 reactivation. J Infect, 80(5):e14-e17. https://doi.org/10.1016/j.jinf.2020.03.001

Yuan J, Zou RR, Zeng LJ, et al., 2020. The correlation between viral clearance and biochemical outcomes of 94 COVID-19 infected discharged patients. Inflamm Res, 69(6):599-606. https://doi.org/10.1007/s00011-020-01342-0

Zhang BC, Zhou XY, Qiu YR, et al., 2020. Clinical characteristics of 82 cases of death from COVID-19. PLOS ONE, 15(7):e0235458.

https://doi.org/10.1371/journal.pone.0235458

Zhao WP, Wang Y, Tang YF, et al., 2020. Characteristics of children with reactivation of SARS-CoV-2 infection after hospital discharge. Clin Pediatr, 59(9-10):929-932. https://doi.org/10.1177/0009922820928057

Zhou L, Liu K, Liu HG, 2020. Cause analysis and treatment strategies of "recurrence" with novel coronavirus pneumonia (COVID-19) patients after discharge from hospital. Chin J Tuberc Respir Dis, 43(4):281-284 (in Chinese). https://doi.org/10.3760/cma.j.cn112147-20200229-00219

Zhuo L, Wei FF, Zhou JQ, et al., 2020. Factors influencing the outcome of 34 patients with COVID-19. J Pract Med, 36(14):1861-1865 (in Chinese).

\section{List of electronic supplementary materials}

Table S1 Search strategy of the recurrence cases with COVID-19

Fig. S1 Forest plots of meta-analysis on the proportion of the asymptomatic individuals among the COVID-19 infections

Fig. S2 Forest plots of meta-analysis on clinical characteristics and laboratory findings of the recurrence cases among the COVID-19 infections

Fig. S3 Funnel plot assessing publication bias in studies reporting proportion of recurrence cases among the COVID-19 patients

\section{中文概要}

\section{题 目: 新型冠状病毒肺炎患者出院后 SARS-CoV-2 复阳 的危险因素: 系统评价和 meta 分析}

概 要: 通过检索笁选到 10 项涉及 2071 例新型冠状病毒 肺炎（COVID-19）患者出院后复查严重急性呼 吸综合征冠状病毒 2 型 (SARS-CoV-2) 核酸检 测的研究, 总结其流行病学、临床症状和辅助检 查特征。COVID-19 患者出院后病毒检测复阳病 例占比为 $17.65 \%$, 而年龄较大的患者更有可能病 毒复阳, 临床症状合并咳嗽、咳痰、头晕症状的 患者有 SARS-CoV-2 复阳的风险。此外, 辅助检 查结果呈双侧肺浸润且白细胞、血小板和 $\mathrm{CD}^{+} \mathrm{T}$ 计数降低的患者有 SARS-CoV-2 病毒复阳的风 险。这些因素可以被视为 SARS-CoV-2 复阳的预 警指标, 并可能有助于临床制定个体化管理策 略。

关键词: 复阳病例; 严重急性呼吸综合征冠状病毒 2 型 (SARS-CoV-2)；危险因素; meta 分析 